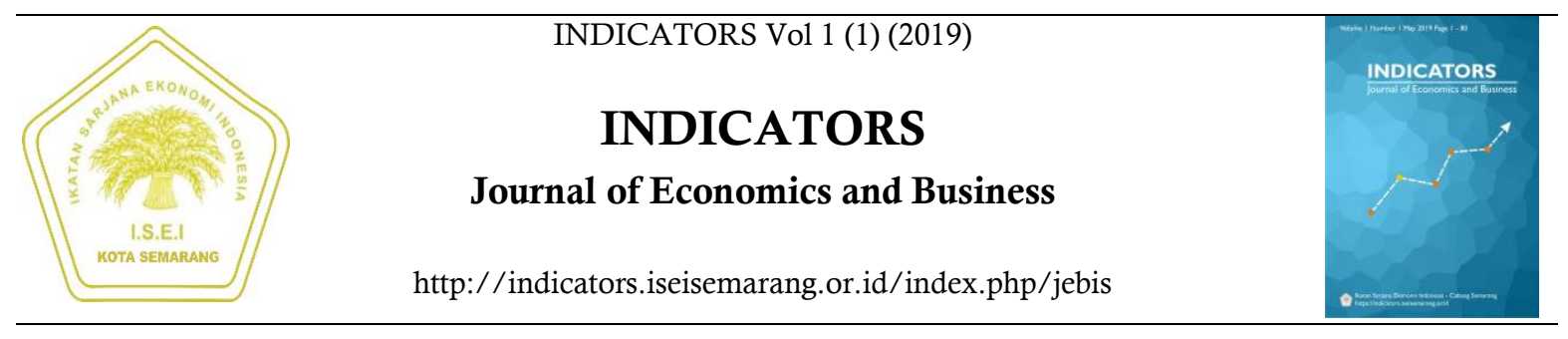

\title{
Evaluasi Pelaksanaan Program Nasional Pemberdayaan Masyarakat Mandiri Perdesaan (PNPM-MP) dalam Menanggulangi Kemiskinan
}

\author{
Ivan Muchtar Sibarani ${ }^{\circledR}$
}

Jurusan Ekonomi Pembangunan, Fakultas Ekonomi, Universitas Negeri Semarang

\begin{tabular}{|c|c|}
\hline Info Artikel & Abstrak \\
\hline $\begin{array}{l}\text { Sejarah Artikel: } \\
\text { Diterima Agustus } 2018 \\
\text { Disetujui Februari } 2019 \\
\text { Dipublikasikan Mei } 2019\end{array}$ & $\begin{array}{l}\text { Penelitian ini bertujuan untuk mengetahui bagaimana partisipasi masyarakat dalam mengikuti } \\
\text { program PNPM-MP di Kecamatan Balige, apakah program PNPM-MP telah tepat sasaran bagi } \\
\text { individu penerima program di Kecamatan Balige dan bagaimana bentuk program sebelum dan } \\
\text { setelah dilaksanakannya program PNPM-MP di Kecamatan. Metode analisis yang digunakan yaitu } \\
\text { analisis deskriptif kualitatif dan kuantitatif dan alat analisis yang digunakan dalam mengevaluasi } \\
\text { proses pemberdayaan adalah dengan model pendekatan evaluasi Fujikake. Hasil penelitian ini } \\
\text { menunjukkan bahwa tingkat partisipasi masyarakat dalam mengikuti program PNPM-MP di } \\
\text { Kecamatan Balige termasuk dalam kategori tinggi ataupun dalam kategori baik, program PNPM- } \\
\text { MP telah tepat sasaran bagi individu penerima program di Kecamatan Balige, bentuk program } \\
\text { PNPM-MP diantaranya pemberian pelatihan pertanian. Saran yang dapat diberikan dari penelitian } \\
\text { ini adalah sebaiknya hasil dari program PNPM mandiri senantiasa dijaga dan diadakan pengecekan } \\
\text { secara berkala agar masyarakat tetap dapat mendapatkan manfaat dari hasil program tersebut, dan } \\
\text { sebaiknya pihak terkait menyelenggarakan program yang setara dengan program PNPM mandiri } \\
\text { mengingat program ini telah terbukti dapat dinikmati oleh masyarakat khususnya masyarakat } \\
\text { pedesaaan. }\end{array}$ \\
\hline
\end{tabular}

\begin{abstract}
This research determine how community participation in program PNPM-MP in sub-district of Balige, whether PNPM-MP has been targeted for individual who receive the program in sub-district of Balige and how the activity in this program before and after the implementation of PNPM-MP in sub-district of Balige. The analytical method used is descriptive qualitative and quantitative analysis, and analytical tools used in evaluating the process of empowerment is Fujikake evaluation approach model. The result showed that the level of community participation in the PNPM-MP program in sub-district of Balige included in the high categories or in both categories, PNPM-MP has been targeted for individuals who receive the program in sub-district of Balige, activity of PNPM-MP including the provision of agricultural training. Advice can be given from this research is the best result of the PNPM Mandiri program always maintained and held periodical check so that people can still get the benefit from the results of the program, and preferably related parties set up a program that is equivalent to the PNPM Mandiri program considering the program has provem to be enjoyed by people, particularly rural communities.
\end{abstract}

\footnotetext{
${ }^{\square}$ Alamat korespondensi:

J1. Erlangga Tengah No.17, Semarang, 50229

E-mail: ivanmuchtarsibarani@ymail.com
} 


\section{PENDAHULUAN}

Tujuan pembangunan nasional salah satunya adalah meningkatkan kinerja perekonomian agar mampu menciptakan lapangan kerja dan menata kehidupan yang layak bagi seluruh rakyat yang pada gilirannya akan mewujudkan kesejahteraan bagi masyarakat Indonesia. Sasaran pembangunan nasional adalah menurunkan jumlah penduduk miskin, karena kemiskinan merupakan salah satu masalah ekonomi yang harus diatasi. Penanggulangan kemiskinan harus dilakukan secara menyeluruh, yang berarti menyangkut seluruh penyebab kemiskinan. Beberapa diantaranya yang menjadi bagian dari penanggulangan kemiskinan tersebut yang perlu tetap ditindaklanjuti dan disempurnakan implementasinya adalah perluasan akses kredit pada masyarakat miskin, peningkatan pendidikan masyarakat, perluasan lapangan kerja.

Tabel 1. Jumlah Rumah Tangga Miskin (RTM) Kecamatan Balige 2010-2013

\begin{tabular}{ll}
\hline Tahun & Jumlah RTM \\
\hline 2010 & $3.041 \mathrm{KK}$ \\
2011 & $2.164 \mathrm{KK}$ \\
2012 & $2.463 \mathrm{KK}$ \\
2013 & $1.418 \mathrm{KK}$ \\
\hline
\end{tabular}

Sumber: PNPM Kecamatan Balige 2013

Berdasarkan tabel 1 dapat di lihat bahwa pada tahun 2010 jumlah rumah tangga miskin di Kecamatan Balige sebanyak 3.041 KK. Pada tahun 2011 RTM Kecamatan Balige menurun menjadi $2.164 \mathrm{KK}$. Kemudian meningkat lagi pada tahun 2012 menjadi 2.463 KK. Dan keadaan ini menurun lagi pada tahun 2013 sebanyak 1.418 KK. Meskipun RTM di Kecamatan Balige turun setiap tahunnya, tapi dengan jumlah RTM 1.418 KK ini masih dirasakan tinggi oleh BPS Toba Samosir. Masih tingginya angka kemiskinan di kecamatan Balige ini disebabkan karena tidak sebandingnya jumlah pertumbuhan angkatan kerja dengan laju pertumbuhan kesempatan kerja, dan juga rendahnya kompetensi tenaga kerja, yang menyebabkan angkatan kerja yang begitu besar di kecamatan Balige tidak terserap secara optimal.

Berbagai program nasional juga sudah banyak dikeluarkan pemerintah salah satunya adalah PNPM-P2KP. Program Penggulangan Kemiskinan di Perkotaan (P2KP) dilaksanakan sejak tahun 1999 sebagai upaya pemerintah untuk membangun kemandirian masyarakat dan pemerintah daerah dalam menanggulangi kemiskinan secara berkelanjutan. Program ini sangat strategis karena menyiapkan landasan kemandirian masyarakat berupa "Lembaga Kepimpinan Masyarakat" yang representatif, mengakar dan kondusif bagi perkembangan modal sosial (social capital) masyarakat di masa mendatang serta menyiapkan program masyarakat jangka menengah dalam penaggulangan kemiskinan yang menjadi pengikat dalam kemitraan masyarakat dengan pemerintah daerah dan kelompok peduli setempat.

Tujuan umum dari PNPM Mandiri Perdesaan adalah meningkatkan kesejahteraan dan kesempatan kerja masyarakat miskin secara mandiri, dengan demikian secara khusus tujuan PNPM Mandiri Perdesaan adalah masyarakat di kelurahan peserta program menikmati perbaikan sosial ekonomi dan tata pemerintahan lokal.

Program PNPM-MP dirancang sebagai bagian dari proses percepatan penanggulangan kemiskinan melalui peningkatan kemampuan kelembagaan masyarakat dan aparat, dengan memberikan modal usaha untuk pengembangan usaha ekonomi produktif dan pembangunan prasarana dan sarana yang mendukung kegiatan ekonomi pedesaan. Program ini juga dirancang sebagai proses pembelajaran (learning) bagi masyarakat maupun aparat melalui proses kegiatan pengambilan keputusan yang demokratis, baik dalam perencanaan, pelaksanaan dan pelestarian kegiatan.

Program Nasional Pemberdayaan Masyarakat Mandiri Perdesaan (PNPM-MP) adalah salah satu program dalam menanggulangi kemiskinan dengan dana yang sangat besar. Maka dengan sebuah asumsi jika hasil evaluasi program ini bisa berjalan dengan baik dan evaluasi bisa dilakukan secara komprehensif dan 
jujur dengan memenuhi kaidah-kaidah ilmiah penelitian, maka program ini diharapkan akan dapat menjadi program unggulan Pemerintah Kabupaten dan Pusat karena akan sangat membantu pemerintah menanggulangi kemiskinan.

Adapun tujuan yang ingin dicapai dari penelitian ini adalah untuk mengevaluasi: (1) partisipasi masyarakat dalam mengikuti program PNPM-MP di Kecamatan Balige. (2) program PNPM-MP telah tepat sasaran bagi individu penerima program di Kecamatan Balige. (3) bentuk program sebelum dan setelah dilaksanakannya program PNPM-MP di Kecamatan Balige. Kemiskinan menurut Suparlan (1993:3) adalah suatu standar tingkat hidup yang rendah yaitu adanya suatu tingkat kekurangan materi pada sejumlah orang dibandingkan dengan standar kehidupan yang umum berlaku dalam masyarakat bersangkutan. Standar kehidupan yang rendah ini secara langsung tampak pengaruhnya terhadap kesehatan, kehidupan moral dan rasa harga diri dari mereka yang tergolong orang miskin.

Bappenas (dalam Diah, 2007:21) mendefinisikan kemiskinan sebagai kondisi dimana seseorang atau sekelompok orang, lakilaki dan perempuan, tidak mampu memenuhi hak dasarnya untuk mempertahankan dan mengembangkan kehidupan yang bermartabat. Hak-hak dasar masyarakat antara lain, terpenuhinya kebutuhan pangan, kesehatan, pendidikan, pekerjaan, perumahan, air bersih, pertanahan, sumberdaya alam dan lingkungan hidup, rasa aman dari perlakukan atau ancaman tindak kekerasan, dan hak untuk berpartisipasi dalam kehidupan sosial-politik, baik bagi perempuan maupun laki-laki.

Menurut Rutman (1984) Evaluasi program adalah suatu kegiatan yang membutuhkan metode ilmiah untuk mengukur implementasi dan hasil program dengan tujuan untuk membuat keputusan. Secara terperinci Owen menerangkan bahwa evaluasi program adalah suatu proses menguraikan menjabarkan informasi untuk menjelaskan dan memahami suatu program, menetapkan keputusan berkaitan dengan program tersebut. Berdasarkan pengertian evaluasi program di atas menunjukkan bahwa evaluasi program adalah serangkaian kegiatan sistematis untuk mengumpulkan data dan informasi sebagai masukan untuk pengambilan keputusan terhadap program yang dievaluasi.

Menurut Setiawan (1999:20) menyatakan bahwa tujuan evalusi program adalah agar dapat diketahui dengan pasti apakah pencapaian hasil, kemajuan dan kendala yang dijumpai dalam pelaksanaan program dapat dinilai dan dipelajari untuk perbaikan pelaksanaan program dimasa yang akan datang. Dengan kata lain, evaluasi dapat pula digunakan untuk melihat apakah proses pelaksanaan suatu kebijakan telah dilaksanakan sesuatu dengan petunjuk teknis/pelaksanaan yang telah ditentukan. Adapun dalam penelitian ini, peneliti menggunakan tipe evaluasi proses yaitu dengan mendasarkan pada petunjuk pelaksanaan ataupun petunjuk teknis dari program PNPMMP dalam bidang ekonomi.

\section{METODE PENELITIAN}

Pada penelitian Evaluasi PNPM Mandiri ini, penulis melakukan penelitian dengan metode penelitian kuantitatif. Menurut Sugiyono (2012:23) dikatakan metode kuantitatif karena data penelitian berupa angka-angka dan analisis menggunakan statistik. Alat analisis yang digunakan dalam penelitian ini dengan menggunakan model pemberdayaan Fujikake. Berdasarkan latar belakang dan rumusan masalah yang telah disebutkan di atas, maka penelitian ini menggunakan model pemberdayaan Fujikake untuk mengevaluasi Program Nasional Pemberdayaan Masyarakat Perdesaan (PNPM-MP) di Kecamatan Balige Kabupaten Toba Samosir.

\section{HASIL DAN PEMBAHASAN}

Tahap pertama model pemberdayaan Fujikake dalam mengevaluasi pelaksanaan PNPM Mandiri adalah melihat perubahan masyarakat dari tingkat kesadarannya. Dapat kita lihat dari beberapa indikator yang terdapat pada tabel 2 di bawah bahwa antusiasme ataupun partisipasi masyarakat dalam mengikuti 
program yang dijalankan pemerintah sudah dalam kategori tinggi ataupun baik.

Tabel 2. Deskripsi partisipasi responden

\begin{tabular}{llrr}
\hline \multicolumn{1}{c}{ Interval Persen } & \multicolumn{1}{c}{ Kriteria } & Frekuensi & Persentasi \\
\hline $81,26 \%-100 \%$ & Sangat Baik & 3 & $3.2 \%$ \\
$62,51 \%-81,25 \%$ & Baik & 76 & $81.7 \%$ \\
$43,76 \%-62,50 \%$ & Tidak baik & 14 & $15.1 \%$ \\
$25 \%-43,75 \%$ & Sangat tidak baik & 0 & $0.0 \%$ \\
\hline & Jumlah & 93 & $100 \%$ \\
\hline
\end{tabular}

Sumber: Data primer diolah 2017

Berdasarkan tabel di atas diperoleh keterangan banyaknya responden yang ikut berpartisipasi sangat baik dalam program PNPM mandiri di perdesaan kecamatan Balige adalah 3 orang $(3,2 \%)$, banyaknya responden yang ikut berpartisipasi dengan kategori baik dalam program PNPM mandiri di perdesaan kecamatan Balige adalah 76 orang $(81,7 \%)$, banyaknya responden yang ikut berpartisipasi dengan kategori tidak baik dalam program PNPM mandiri di perdesaan kecamatan Balige adalah 14 orang $(15,1 \%)$. Dapat dilihat bahwa respon masyarakat dalam pelaksanaan program PNPM Mandiri di Kecamatan Balige termasuk dalam kategori tinggi atau sudah dalam kategori baik, dimana partisipasi masyarakat dalam mengikuti setiap program-program yang telah dilaksanakan memberikan respon yang baik ataupun respon yang tinggi yakni sebesar $81,7 \%$.

Selanjutnya tahap kedua ini bagaimana mengevaluasi pemberdayaan dengan menilai tanggapan masyarakat dan praktik pemberdayaan yang didasarkan pada penilaian terhadap 12 indikator. Kemauan masyarakat untuk terlibat terlihat pada saat masyarakat ikut partisipasi pada kegiatan- kegiatan yang dilaksanakan oleh PNPM.

Sikap kritis warga dalam menyampaikan usulan atau program pelatihan yang akan dijalankan oleh warga. Usulan program yang diusulkan masyarakat ini didasarkan dengan kesadaran dan keinginan untuk mengubah kondisinya yang lebih baik dari kondisi sekarang. Kemampuan warga dalam mengindentifikasi dan mengetahui akar permasalahan kemiskinan yang ada di lingkungan masyarakat, memudahkan terbentuk kegiatan pelatihan ini.

Tindakan untuk berperan aktif dalam kegiatan pelatihan dalam bidang pertanian sudah terlihat dengan adanya beberapa orang peserta pelatihan mengerti betul apa yang akan didapatkan pada saat pelatihan. Keinginan untuk mengubah kondisinya sekarang menjadi motivasi dan semangat tersendiri bagi peserta pelatihan di Kecamatan Balige. Motivasi inilah yang menjadi dasar masyarakat menjadikan pelatihan dalam bidang pertanian sebagai program kegiatan yang difasilitasi oleh PNPMMP. Hal ini terlihat pada saat masyarakat aktif dalam mengikuti pelatihan sebagai program prioritas di lingkungan mereka.

Keberadaan pelatihan dalam bidang pertanian ini memberikan modal bagi masyarakat untuk meningkatkan hasil produksi pertanian masyarakat. Tingkat kepuasan masyarakat terhadap hasil-hasil kegiatan pelatihan melalui pelatihan dalam bidang pertanian dilaksanakan cukup baik, disamping itu masyarakat juga menyatakan kepuasannya terhadap proses pelaksanaan pekerjaan yang dilaksanakan.

Selanjutnya pada tahap ketiga adalah mengelompokkan dan menghubungkan antar indikator yang telah dianalisis pada tahap sebelumnya dari ke 12 indikator (tingkat partisipasi, pengemukaan opini, perubahan kesadaran, pengambilan tindakan, kepedulian dan kerjasama, kreativitas, menyusun tujuan baru, negosiasi, kepuasan, kepercayaan diri, keterampilan manajerial, dan pengumpulan 
keputusan) dikelompokkan menjadi 4 elemen inti pemberdayaan yaitu ekonomi, sosial budaya, mobilitas dan kesadaran.

Ekonomi, kegiatan dalam penguatan ekonomi secara langsung dapat dilihat dari kegiatan PNPM meningkatkan keterampilan masyarakat, dengan adanya pelatihan dalam bidang pertanian oleh PNPM mampu meningkatkan hasil produksi pertanian masyarakat, dan juga kegiatan PNPM meningkatkan pendapatan masyarakat sehingga dengan adanya perubahan dalam kegiatankegiatan tersebut dapat mengurangi tingkat kemiskinan di Kecamatan Balige.

Sosial dan Budaya, secara sosial budaya dalam setiap kegiatan musyawarah untuk kegiatan PNPM masyarakat dilibatkan, kegiatan PNPM menumbuhkan jiwa berorganisasi masyarakat dan juga kegiatan PNPM menumbuhkan rasa kepedulian dan tanggung jawab masyarakat terhadap setiap program yang telah terlaksana. Dalam pelaksanaan kegiatan fisik seperti pembangunan jalan, saluran irigasi dan lain-lain semua masyarakat dilibatkan. Rasa kekerabatan ini terlihat dengan saling peduli dan kerjasama diantara masyarakat. Masyarakat memberikan ide dalam kegiatan PNPM. Selain itu, sikap saling menghargai pendapat satu sama lain dan saling menghormati diantara mereka tetap dipertahankan oleh masyarakat yang berada di Kecamatan Balige.

Mobilitas, sengan penguatan ekonomi ini menjadikan secara langsung masyarakat di Kecamatan Balige telah mengalami perubahan sosial yang telah mendapatkan penghasilan dalam penguatan ekonomi masyarakat dan tidak lagi hidup dalam garis kemiskinan.

Kesadaran, perubahan-perubahan kesadaran ini akan senantiasa menjadi pendorong dan memotivasi warga dalam mengubah kondisinya yang lebih baik dari yang sekarang. Karena itu perlu daya kreativitas untuk memeunculkan ide-ide baru dalam memecahkan persoalan-persoalan lingkungan yang ada.

Selanjutnya pada tahap keempat Fujikake mengukur tingkatan pencapaian pemberdayaan itu sendiri dengan menggolongkan menjadi tiga yaitu micro level (desa), meso level (kota/wilayah), dan macro level (nasional). Jika dilihat dari pelatihan dalam bidang pertanian ini maka pengaruh terhadap lingkungan maka masih dirasakan pada lingkup micro level. Namun secara eksplisit, adanya program ini telah melibatkan semua pihak yang terkait dalam proses pemberdayaan baik dari tingkat Kota/Wilayah dan tingkat Nasional. Analisis tingkatan pemberdayaan, serta pencapaian keberdayaan masyarakat dan keberlanjutan terhadap program pengembangan masyarakat tersebut penting dilakukan ketika akan dilakukan sebuah evaluasi terkait comunity empowerment evaluation sejauh mana dapat mencapai tujuan dan target yang telah ditetapkan sebelumnya, serta Pemerintah dan tim fasilitator perlu memfasilitasi terbentuknya jaringan kerja yang lebih luas antar semua stakeholder pembangunan untuk menjamin keberlanjutan program pemberdayaan masyarakat khususnya di tingkat komunitas.

\section{SIMPULAN}

Berdasarkan hasil penelitian dan pembahasan di atas dapat diambil kesimpulan sebagai berikut: (1) Tingkat partisipasi masyarakat dalam mengikuti program PNPMMP di Kecamatan Balige termasuk dalam kategori tinggi ataupun dalam kategori baik, yaitu sebesar 70,6\%. (2) Program PNPM-MP telah tepat sasaran bagi masyarakat penerima program PNPM di Kecamatan Balige terbukti dengan adanya perubahan tingkat kesejahteraan ekonomi pada masyarakat balige dan (3) Bentuk program PNPM-MP di Kecamatan Balige diantaranya adalah pemberian pelatihan dalam bidang pertanian dimana masyarakat sebelumnya tidak paham menjadi lebih paham tentang pertanian.

\section{DAFTAR PUSTAKA}

Abubakar, H, 2013. Pengaruh Program Nasional Pemberdayaan Masyarakat Mandiri Perkotaan (PNP-MP) Terhadap Peningkatan Pendapatan Masyarakat Miskin di Kota Banda Aceh. Universitas Syiah Kuala. Banda Aceh.

Arif,S, 2000. Pengantar sosiologi Masyarakat Pesisir. Pustaka Cesindo. Jakarta.

Bappenas, 2004. Rencana Strategik Penanggulangan Kemiskinan di Indonesia, Jakarta. 
Chambers, R, 1988. Pembangunan Desa; Mulai dari Belakang", LP3ES, Jakarta.

Desyani, 2013. Analisis Pelaksanaan Program Nasional Pemberdayaan Masyarakat Mandiri (PNPM Mandiri) di Kelurahan Sidodadi Samarinda Ulu. Unmul

Devi Nafiana, S.STP, dkk, 2011. Pengaruh Pinjaman Bergulir Program Nasional Pemberdayaan Masyarakat Mandiri Perkotaan (PNPM-MP) Terhadap Konsumsi Rumah Tangga di Kota Tasikmalaya. Universitas Padjajaran. Bandung.

Dunn, William, 1999. Pengantar Analisis Kebijakan Publik. Yogyakarta: Gadjah Mada University Press.

Dyah Ratih. 2007. Pembangunan Pendidikan Dan Mdgs Di Indonesia: Sebuah Refleksi Kritis. Jurnal Kependudukan Indonesia, Vol.2 No.2. Jakarta.

Fujikake, Yoko, 2008. Qualitative Evaluation: Evaluating People's Empowerent, Japanese Journal of Evaluation Studies, Vol 8 No 2, 2008, pp 25 -37, Japan Evaluation Society.

Kuncoro, Mudrajat, 2003. Ekonomi Pembangunan, Teori Masalah dan Kebijakan. Penerbit Erlangga: Jakarta.

Kusumandari, R. (2015). Peran PNPM Dalam Upaya Mobilitasi Masyarakat Miskin Di Kota Semarang. JEJAK: Jurnal Ekonomi Dan Kebijakan,

Moleong, Lexy J, 2004. Metodologi Penelitian Kualitatif. Bandung: PT. Remaja Rosda Karya.

Mubarak, Z, 2010. Evaluasi Pemberdayaan Masyarakat Ditinjau Dari Proses Pengembangan Kapasitas Pada Kegiatan Pnpm Mandiri Perkotaan Di Desa Sastrodirjan Kabupaten Pekalongan. Tesis Universitas Diponegoro, Semarang.

Mubyarto, 1990. Sistem dan Moral Ekonomi Indonesia, cetakan kedua, LPES, Jakarta.

Nirmaladewi Binti Marfin dan Djuara P. Lubis, 2011. Persepsi dan Motivasi Relawan dalam Melaksanakan Program Nasional Pemberdayaan Masyarakat Mandiri Perkotaan. Departemen Sains Komunikasi dan Pengembangan Masyarakat, Fakultas Ekologi Manusia, IPB. Bogor.

Prihartini, B, A, 2010. Efektivitas dan Pengaruh PNPM Mandiri Perdesaan, Alokasi Dana Desa, Pendapatan Asli Desa dan Jumlah Penduduk Terhadap Jumlah Kepala Keluarga Miskin di Kabupaten Kebumen Tahun 2009-2011.

Rarun Virginia Heidy, dkk, 2011. Program Nasional Pemberdayaan Masyarakat (PNPM) di
Kelurahan Taratara I Kecamatan Tomohon Barat Kota Tomohon. Program Studi S2 Administrasi Negara, Program Pascasarjana Universitas Negeri Manado.

Sagala, Otto Dwana, 2009. Evaluasi Program Nasional Pemberdayaan Mandiri Perdesaan Terhadap Pengembangan Sosio-Ekonomi dan Kesejahteraan Masyarakat di Kecamatan Balige Kabupaten Toba Samosir. Tesis Sekolah Pascasarjana Universitas Sumatera Utara, Medan.

Salim, Emil, 1984. Pembangunan Berwawasan Lingkungan, Jakarta: P.T.Pustaka LP3ES.

Sekaran, Uma, 2006. Research Methods for Business. Fourth Edition. Jakarta: Salemba Empat.

Setiawan, 1999. Evaluasi Proyek: Pengertian Evaluasi Proyek, Aspek-Aspeknya dan Metode Memperoleh Gagasan. Bappenas. Jakarta.

Sudjana, Prof. Djudju, M.Ed, Ph.D. 2006. Evaluasi Program Pendidikan Luar Sekolah. Bandung: Rosdakarya.

Sugiyono, 2012. Memahami penelitian Kualitatif. Bandung: ALFABETA.

Suharto, Edi, 2005. Analisis Kebijakan Publik: Panduan Praktis Mengkaji Masalah dan Kebijakan Sosial. Bandung: Alfabeta.

Sulistiyani, Ambar T dan Rosidah, 2009. Manajemen Sumber Daya Manusia. Yogyakarta: Graha Ilmu.

Suman, Agus , 2006. Strategi Pembangunan Menuju Indonesia Baru. Pascasarjana, Universitas Brawijaya. Malang Sunyoto, D, 2011. Metode Penelitian Untuk Ekonomi. Yogyakarta: Caps.

Suparlan, Parsudi, 1993. Kemiskinan di Perkotaann. Yayasan Obor Indonesia. Jakarta.

Suryawati, C, 2005. Memahami Kemiskinan Secara Multidimensional. http://www.jmpk-online.net.

Sutisna, Oteng. 2000. Administrasi Pendidikan Dasar Teoretis untuk Praktek Profesional. Bandung.Angkasa.Tayibnapis, Farida Yusuf, 2000. Evaluasi Program. Jakarta: PT. Rineka Cipta.

Tayibnapis, Farida Yusuf, 2000. Evaluasi Program. Jakarta: PT. Rineka Cipta.

TNP2K, 2011. Daftar Lokasi dan Alokasi Bantuan Langsung Masyarakat (BLM) Program Nasional Pemberdayaan Masyarakat Mandiri (PNPM Mandiri) Tahun Anggaran 2011. Jakarta: Buku Pedoman Umum

2012. Daftar Lokasi dan Alokasi Bantuan Langsung Masyarakat (BLM) Program Nasional Pemberdayaan Masyarakat Mandiri (PNPM 
Mandiri) Tahun Anggaran 2012. Jakarta: Buku Pedoman Umum.

2013. Daftar Lokasi dan Alokasi Bantuan Langsung Masyarakat (BLM) Program Nasional Pemberdayaan Masyarakat Mandiri (PNPM Mandiri) Tahun Anggaran 2013. Jakarta: Buku Pedoman Umum.

2014. Daftar Lokasi dan Alokasi Bantuan Langsung Masyarakat (BLM) Program Nasional Pemberdayaan Masyarakat Mandiri (PNPM Mandiri) Tahun Anggaran 2014. Jakarta: Buku Pedoman Umum.

Todaro, M, P, 2003. Pembangunan Ekonomi di Dunia Ketiga. Jilid 1 dan 2. Terjemahan Haris Munandar. Jakarta: Erlangga.

Todaro, Michael P. and Smith, 2006, Pembangunan Ekonomi, Edisi Kesembilan, Erlangga: Jakarta.
Tri Septin M,R dan Wida Purwidianti, 2014. Pengaruh Program Pemberdayaan Masyarakat Pedesaan Terhadap Tingkat Pendapatan Masyarakat Di Kecamatan Kedungbanteng Kabupaten Banyumas. Universitas Muhammadiyah Purwokerto. Purwokerto.

Usman, Husaini \& Purnomo Setiady Akbar, 2008. Metodologi Penelitian Sosial, Jakarta: PT. Bumi Aksara.

Widodo, Triyogo, 2006. Pemberdayaan Masyarakat Miskin Sekitar Hutan Melalui Pengembangan Kelembagaan Pengelolaan Hutan Berbasis Masyarakat. Disertasi IPB, Bogor.

Widodo Wahyu, 2014. Efektivitas Program Pinjaman Bergulir PNPM Mandiri Perkotaan dalam Penanggulangan Kemiskinan di Kabupaten Sangihe.

World Bank, 1989. Indonesia: Basic Education Study. Washington D.C.:World Bank. 